\title{
DOCTORATES CONFERRED IN 1959
}

The following are among those who received doctorates in the mathematical sciences and related subjects from universities in the United States and Canada during 1959. In each case when available, the university, the month in which the degree was conferred, minor subjects (other than mathematics), and title of dissertation are given.

Note that there is included at the end of these Notes a list of doctorates conferred in 1958 and one in 1957 that have not been included in previous lists of doctorates conferred.

J. H. Abbott, University of Illinois, June, minor in Electrical Engineering, Topics in information theory.

John Abramowich, University of California, Berkeley, January, A generalized summation by parts.

A. E. Albert, Stanford University, October, The sequential design of experiments for infinitely many states of nature.

H. N. Albright, University of Pennsylvania, February, Compact complex homogeneous manifolds.

W. L. Allen, University of Florida, January, minor in Logic, Complex groups.

W. S. Ament, Brown University, June, minor in Physics, Wave propagation in suspensions.

J. M. Anderson, Iowa State University, August, minor in Physics, Network rings and algebras.

A. R. Ansari, Virginia Polytechnic Institute, June, Two-way-rank sum tests for variances.

K. I. Appel, University of Michigan, June, Two investigations on the borderline of logic and algebra.

M. L. Balinski, Princeton University, June, An algorithm for finding all vertices of convex polyhedral sets.

C. S. Ballantine, Stanford University, January, A study of some semigroups of Moebius transformations.

D. O. Banks, Carnegie Institute of Technology, June, Bounds for the eigenvalues of some vibrating systems.

Hyman Bass, University of Chicago, June, Global dimensions of rings.

N. W. Bazley, University of Maryland, June, minor in Physics, Lower bounds for eigenvalues.

R. E. Beckwith, Purdue University, June, Analytic and computational aspects of dynamic programming processes of high dimension. 
P. E. Bedient, University of Michigan, January, Polynomials related to Appell functions of two variables.

D. W. Behnken, North Carolina State College, August, Simplexsum designs- $A$ class of second order rotatable designs derivable from those of first order.

D. J. Benney, Massachusetts Institute of Technology, September, minor in Aeronautical Engineering, On the secondary motion induced by oscillations in a shear flow.

S. A. Berger, Brown University, June, Spherical explosions in sea water.

I. S. Bernstein, Massachusetts Institute of Technology, June, minor in Physics, On the unique continuation problem of elliptic partial differential equations.

W. A. Beyer, Pennsylvania State University, January, minor in Physics, Besicovitch dimension of level sets of Rademacher series.

V. P. Bhapkar, University of North Carolina, August, Contributions to the statistical analysis of experiments with one or more expanses (not necessarily normal).

J. H. Bick, Brown University, June, A continuum model for traffic flow on an undivided highway.

G. G. Bilodeau, Harvard University, June, Inversion and representation theory for the Weierstrass transform.

J. E. Bishop, University of Chicago, June, On summability of double series.

R. L. Bishop, Massachusetts Institute of Technology, June, On imbeddings and holonomy.

J. W. Blattner, University of California, Los Angeles, August, Three-variable identities in Jordan algebras.

J. L. Boal, Massachusetts Institute of Technology, September, minor in Mechanical Engineering, Axisymmetric deformations of bodies with polar orthotropy.

J. R. Boen, University of Illinois, October, minor in Electrical Engineering, On P-groups of class 3 generated by 3 elements.

A. J. Bonis, George Washington University, June, Solutions to problems in Solomon Kullback's "Information theory and statistics."

B. J. Boyer, Purdue University, January, Summation of trigonometric series by a generalization of the Cesàro method.

P. G. Braunfeld, University of Illinois, February, minor in Philosophy, Two characterizations of a class of Matebelian P-groups.

L. S. Brenna, Virginia Polytechnic Institute, June, Factorial treatments in lattice designs.

D. G. Brennan, Massachusetts Institute of Technology, June, 
minor in Physics, On the pathological character of independent random variables.

Louis Brickman, University of Pennsylvania, June, $A$ new generalization of a problem of $F$. Lukacs.

T. F. Bridgland, Jr., University of Florida, June, minor in Engineering Mechanics, Linear filters on a sequence space.

E. A. Brown, Ohio State University, March, Algorithms for the hand-computation solution of the transhipment problem and maximum flow in a restricted network.

A. M. Bruckner, University of California, Los Angeles, August, Minimal superadditive extensions of superadditive functions.

R. N. Buchal, New York University, June, Boundary layer problems in diffraction theory.

Terence Butler, Indiana University, June, minor in Mechanics, A mathematical example displaying features of turbulence.

E. D. Callender, Jr., Stanford University, June, n-dimensional quasi-conformal mappings.

G. T. Cargo, University of Michigan, June, Boundary behavior of Blaschke products.

R. W. Carroll, University of Maryland, June, On some generalized Cauchy problems and the convexity of their solutions.

H. P. Carter, Vanderbilt University, June, minor in Physics, Modular lattices induced by finite groups.

J. G. Ceder, University of Washington, June, Some generalizations of metric spaces.

V. J. Chacko, University of California, Berkeley, June, Testing homogeneity against ordered alternatives.

Bomshik Chang, University of British Columbia, May, minor in Physics, On Engel rings of exponent $p-1$ over $G F(p)$.

G. G. Chapin, Jr., University of Minnesota, March, minor in Chemical Engineering, One and two point boundary value problems for ordinary linear differential equations containing a parameter.

P. L. Chessin, University of Maryland, January, Free radical statistics.

Chia-Kun Chu, New York University, February, Type-insensitive finite difference methods.

Hsin Chu, University of Pennsylvania, June, Groups and semigroups in topological dynamics.

R. E. Clark, University of North Carolina, June, On some theorems of Ostmann on the asymptotic density of the sum of sets of positive integers.

Whitfield Cobb, University of North Carolina, June, Contributions 
to univariate or multivariate analysis of variance with fixed effects, normal or nonnormal random effects, and normal error.

W. D. Commins, Jr., Stanford University, June, Asymptotic variance as an approximation to expected loss for maximum likelihood estimates.

Paul Concus, Harvard University, June, Effects of a magnetic field on natural convection in a toroidal channel.

E. H. Connell, Stanford University, June, Properties of fixed point spaces.

F. F. Connor, Illinois Institute of Technology, January, Concerning the equivalence of Lebesgue-Stieltjes summability classes.

G. R. Cowper, Brown University, June, On the continuing deformation of work-hardening plastic solids.

D. W. Crowe, University of Michigan, June, Finite groups generated by unitary reflections in two dimensions.

H. L. Crowson, University of Florida, June, minor in Chemical Engineering, $A$ study of a linear ordinary second order differential equation with five regular singular points.

W. J. A. Culmer, University of Minnesota, December, minor in Physics, Convergent solutions of ordinary linear homogeneous difference equations in the neighborhood of an irregular singular point.

P. M. Cuttle, University of Oregon, June, Scalar transformations in quasi reflexive spaces.

Yvonne Cuttle, University of Oregon, June, The geometry of the unit sphere and variations of reflexivity.

Aubert Daigneault, Princeton University, June, Products of polyadic algebras and of their representations.

G. L. Davey, Stanford University, April, An investigation of the flow of a viscous compressible fluid past a semi-infinite flat plate at zero angle of attack.

E. K. Dorff, Lehigh University, June, Banach algebras of infinite matrices and applications to the theory of summability.

R. E. Dowds, Purdue University, January, Vector and operator valued Radon measures and distributions.

R. J. Driscoll, Northwestern University, June, Existence theorems for certain classes of two-point boundary problems by variational methods.

R. M. Durstine, Harvard University, March, Part I. Edge wave motion over a shelf; Part II. Stability of an unbounded parallel flow for small Reynolds number.

S. F. Ebey, Northwestern University, August, The classification of singularities of curves by means of their complete local rings. 
N. G. Einspruch, Brown University, June, Scattering of elastic waves in isotropic media by spherical obstacles.

Martin Eisen, University of Toronto, November, Piecewise analytic solutions of mixed boundary value problems.

Edmund Eisenberg, Brown University, June, Aggregation of utility functions.

E. O. Elliott, University of California, Berkeley, June, Finite and infinite product measures.

George Epstein, University of California, Los Angeles, June, The lattice theory of Post algebras.

A. J. Fabens, Stanford University, June, Limiting distributions for some problems in inventory theory.

R. H. Farrell, University of Illinois, October, minor in Electrical Engineering, Sequentially determined bounded length confidence intervals.

Lawrence Fearnley, University of Utah, June, Continuous mappings of the pseudo-arc.

A. N. Feldzamen, Yale University, June, Semi-similarity invariants for spectral operators on Hilbert space.

W. E. Felling, St. Louis University, June, Mills' ratio and linear truncation for some Pearson curves.

R. W. Ferguson, University of Pittsburgh, June, Analytical techniques for the solution of non-linear power system equations and their application to economic problems.

P. C. Fife, New York University, June, An elastic plate problem with boundary layer: asymptotic treatment and a priori pointwise estimates.

R. J. P. de Figueiredo, Harvard University, March, minor in Physics, Existence and uniqueness of periodic solutions in autonomous oscillators.

G. M. Fisher, Louisiana State University, August, On the group of all homeomorphisms of a manifold.

Paul Fong, Harvard University, June, On the characters of finite solvable groups.

Auguste Forge, Duke University, June, minor in Physics, Three theorems in dimension theory.

B. L. Foster, University of Washington, March, Differentiation on manifolds.

Martin Fox, University of California, Berkeley, September, Some zero sum two person games with moves in the unit interval.

Peter Frank, Columbia University, May, Taboo generating functions and other topics in Markov chains. 
R. S. Freeman, University of California, Berkeley, January, Self adjoint boundary conditions for the Laplacian operator.

A. V. Gafarian, University of California, Los Angeles, January, minor in Engineering, On confidence bands in polynomial regression.

P. X. Gallagher, Princeton University, June, Metric diophantine approximation in one and several dimensions.

M. D. George, Princeton University, June, The approximation of solutions of non-linear differential equations.

M. A. Geraghty, Notre Dame University, June, Continuous functions on spheres.

Sister Catherine Josephine Gillis, Boston University, June, Some problems concerning the Wolfowitz two-sample test.

V. E. Giuliano, Harvard University, March, An experimental study of automatic language translation.

J. G. Glimm, Columbia University, September, On a certain class of operator algebras.

I. E. Glover, Oklahoma State University, May, On analytic functions having as singular sets certain closed and bounded sets.

J. L. Goldberg, University of Illinois, June, On positive real functions.

G. H. Golub, University of Illinois, June, minor in Electrical Engineering, The use of Chebyshev matrix polynomials in the iterative solution of linear equations compared to the method of successive overrelaxation.

M. J. Greenberg, Princeton University, June, Pro-algebraic structure on the rational subgroup of a p-adic Abelian variety.

S. W. Greenhouse, George Washington University, June, Information theory and the statistical problem of discrimination.

J. A. Greenwood, Harvard University, June, Distribution theory of some angular variates.

Peter Hagis, Jr., University of Pennsylvania, June, $A$ problem on partitions with a prime modulus $p \geqq 3$.

F. J. Hahn, University of Illinois, June, minor in Philosophy, Stability of set trajectories in a dynamical system.

A. G. Hansen, Case Institute of Technology, June, Similarity solutions of the three-dimensional, laminar, incompressible boundarylayer equations.

W. J. O. Hardell, Michigan State University, March, Left associated elements in a linear algebra.

W. L. Harkness, Michigan State University, September, An investigation of the power function for the test of independence in $2 \times 2$ contingency tables. 
L. R. Harper, Jr., University of Chicago, August, Some properties of partially stable algebras.

R. T. Harris, University of Illinois, October, Generalized eigenfunction expansions for operator algebras.

R. E. Haymond, University of Oregon, June, Topological properties of integer vectors.

R. W. Heath, University of North Carolina, June, Arc-wise connectedness in semi-metric spaces.

G. W. Hedstrom, University of Wisconsin, August, minor in Physics, Absolute convergence of eigenfunction expansions.

B. W. Helton, University of Texas, June, Product integrals.

G. W. Henderson, University of Texas, August, minor in Physics, Proof that every compact continuum which is topologically equivalent to each of its nondegenerate subcontinua is an arc.

E. W. Herron, Duke University, June, Schlaefli's theorem.

J. H. Holland, University of Michigan, June, minor in Philosophy and Psychology, Cycles in logical nets.

F. A. Homann, University of Pennsylvania, February, On some integrals of analytic additive number theory.

R. H. Homer, University of California, Berkeley, June, Abstract extension theory of linear operators in Banach space.

J. E. Houle, Catholic University, June, On sets of matrices with quaternion coefficients.

J. E. Householder, University of Colorado, June, The representation of zero by odd kth power diagonal forms.

R. A. Hultquist, Oklahoma State University, August, Minimal sufficient statistics for Eisenhart's model III.

S. A. Husain, Purdue University, June, Convergence factors and summability of orthonormal expansions.

D. H. Husemoller, Harvard University, June, Mappings, automorphisms, and coverings of Riemann surfaces.

A. B. Ionescu Tulcea, Yale University, June, Ergodic theory of random series.

Cassius Ionescu Tulcea, Yale University, June, Semi-groups of operators.

R. E. Isaac, University of California, Berkeley, September, Some ergodic properties of singular Markov chains.

J. F. Jakobsen, University of Missouri, June, Unstable homeomorphisms and certain continua.

Anatole Joffe, Cornell University, June, Sojourn time for stable processes. 
A. A. Johnson, Case Institute of Technology, June, Direct and indirect representations in the theory of categories.

D. G. Johnson, Purdue University, June, A structure theory for a class of lattice-ordered rings.

D. M. Johnson, University of Toronto, March, Representations of the symmetric group.

J. R. Johnson, Alabama Polytechnic Institute, June, Extensions of the operator $e^{a^{2}} t z^{2}$ and their inversions.

R. S. Johnson, University of Pennsylvania, February, On monosplines of least deviation.

J. T. Joichi, University of Illinois, October, $A$ study of closed operators on Banach spaces.

D. A. Jones, State University of Iowa, June, On the limiting distribution of $-2 \log \lambda$ in the non-regular case.

W. J. Kammerer, University of Wisconsin, August, Optimal approximations of functions: One sided approximation and extrema preserving approximations.

C. R. V. Karp, University of Southern California, January, Languages with expressions of infinite length.

R. M. Karp, Harvard University, March, Some applications of logical syntax to digital computer programming.

I. N. Katz, Massachusetts Institute of Technology, June, minor in Physics, On the existence of weak solutions to linear partial differential equations.

M. W. Katz, University of Illinois, October, minor in Psychology, Admissible and minimax estimates of parameters in truncated spaces.

J. E. Keisler, University of Michigan, June, Quasi-complexes.

C. E. Kerr, Lehigh University, October, Sequence spaces and summability over fields with non-archimedean valuations.

J. M. Kister, University of Wisconsin, August, Isotopies in manifolds.

J. S. Klein, University of Michigan, January, Some results in the theory of Hankel transforms.

T. S. Klotz, New York University, February, On G. Bol's proof of Carathéodory's conjecture.

F. B. Knight, Princeton University, October, Construction of diffusion processes by means of random walks.

W. R. Knight, University of Toronto, November, Exponential and subexponential distributions in statistical life testing.

E. T. Kobayashi, University of Washington, August, Integration of subspaces derived from a linear transformation field. 
S. B. Kochen, Princeton University, January, Ultrafiltered products and arithmetical extensions.

Adam Koranyi, University of Chicago, December, minor in Physics, Operator-theoretic methods applied to interpolation problems for functions of several complex variables.

R. M. Krause, Harvard University, March, Minimal metric spaces.

D. L. Kreider, Massachusetts Institute of Technology, February, minor in Modern Languages, Analytic predicates and extensions of the notion of constructive ordinal.

H. P. Kuang, University of Minnesota, July, The theory of the metric function and its applications.

G. J. Kurowski, Carnegie Institute of Technology, June, Semidiscrete analytic functions.

Nosup Kwak, Duke University, June, minor in Physics, Imbedding of compact metric spaces in cubes.

C. D. La Budde, New York University, February, The evaluation of two and three center integrals arising in calculations on molecular structure.

J. A. Lechner, Princeton University, June, Optimum decision rules for the comparison of two Poisson processes based on minimization of expected loss.

C. N. Lee, University of Virginia, June, Compact zero-dimensional transformation groups.

Harry Lighthall, Jr., Brown University, June, A study of a model of a multi-commodity dynamic economy.

D. B. Lissner, Cornell University, June, Matrices over polynomial rings.

D. H. Lorenz, University of Illinois, October, minor in Physics, Generalized function solutions to the initial value problem for Liouville's equation.

D. A. Ludwig, New York University, February, Propagation of singularities in wave motion.

Gunter Lumer, University of Chicago, August, Numerical range and states.

J. C. McCall, University of Illinois, June, Positive real functions.

C. A. McCarthy, Yale University, June, Operators on a Banach space.

L. R. McCulloh, Ohio State University, June, Integral bases in Kummer extensions of Dedekind fields.

R. H. McDowell, Purdue University, August, Extension of continuous mappings from dense subspaces. 
D. C. McGarvey, Yale University, June, Operators commuting with translation by one.

M. D. McIlroy, Massachusetts Institute of Technology, February, minor in Physics, On the solution of the differential equations of conical shells.

B. H. McLemore, Jr., University of Illinois, October, On test efficiency against normal alternatives.

J. E. Mack, Purdue University, June, The second order dual of the space of Radon measures.

J. C. Mairhuber, University of Pennsylvania, February, I. On Haar's theorem concerning Chebychev approximation problems having unique solutions; II. Boundary values of continuous analytic functions.

D. G. Malm, Brown University, June, On the cohomology ring of a sphere bundle.

C. C. Maneri, Ohio State University, December, A class of simple gamma delta rings.

O. L. Mangasarian, Harvard University, March, Stresses in the plastic range around a normally loaded circular hole in an infinite sheet.

L. N. Mann, University of Pennsylvania, June, Compact Abelian transformation groups.

F. G. Martin, Jr., North Carolina State College, May, minor in Genetics, An empirical study of the effect of linkage on progress from selection.

N. F. G. Martin, Iowa State University, Ames, February, minor in Physics, Metric density of sets.

J. C. Mathews, Iowa State University, Ames, November, minor in Psychology, Fixed point theorem for a contraction mapping in a regular developable space.

C. G. Matthews, University of California, Los Angeles, January, Arithmetic methods for symbolic transformations.

R. D. Mayer, University of Washington, August, Boolean algebras with ordered bases.

B. C. Mazur, Princeton University, June, On embeddings of spheres.

David Mead, Columbia University, May, Linear and nonlinear differential polynomials.

Bert Mendelson, Columbia University, May, $A \mathrm{CW}$-decomposition of the symmetric product of spheres.

M. V. K. Menon, Ohio State University, August, Combined intrablock and interblock estimates.

A. C. Mewborn, University of North Carolina, June, Generalizations of some theorems on positive matrices to completely continuous linear operators in a normed linear space. 
H. C. Miller, Jr., University of North Carolina, August, Regular functions associated with convex sets.

Jack Minker, University of Pennsylvania, February, Some applications of orthogonal systems of functions of interpolation and analytic continuation.

C. L. Miracle, University of Kentucky, August, minor in Physics, The Gibbs phenomenon for the Taylor transform and $\left[F, d_{n}\right]$ transform of the sequence of partial sums of a Fourier series.

Halina Montvila, New York University, June, On the convergence of the numerical solution for a certain partial differential equation of third order.

R. H. Moore, University of Michigan, June, On approximations of the solutions of Goursat problem for second order quasi-linear equations.

J. M. Moser, St. Louis University, June, minor in Economics, Cumulative functions and reliability.

A. A.-K. Muwafi, University of Florida, June, minor in Education, On pairs of diophantine equations.

E. O. Nelson, University of Minnesota, August, $A$ solution of the generalized heat flow equation in a bounded region as a Wiener integral.

W. C. Nemitz, Ohio State University, June, On a decomposition theorem of Mickle.

J. H. Neuwirth, Massachusetts Institute of Technology, June, Singular integrals and the totally hyperbolic equation.

L. P. Neuwirth, Princeton University, June, Knot groups.

Nathan Newman, New York University, June, Maximal gains of antennas.

P. A. Nickel, University of California, Los Angeles, June, Canonical mappings of a bordered Riemann surface.

Togo Nishiura, Purdue University, August, minor in Physics, Analytic theory of continuous transformations.

S. D. Nolte, Iowa State University, Ames, November, Moduli of continuity of quasi-smooth functions.

J. A. Norton, Jr., Purdue University, July, minor in Psychometrics, Tests of hypotheses in the case of unequal variances.

J. D. Novak, Michigan State University, September, Generalizations of curvatures associated with a curve on a surface.

J. E. Ohm, University of California, Berkeley, June, The embedding of an abstract variety in a complete variety.

K. B. O'Keefe, University of California, Berkeley, January, $A$ property of the differential ideal $\left(y^{p}\right)$.

Hiram Paley, University of Wisconsin, August, On Galois subrings of a full ring of linear transformations. 
Samuel Park, University of Pittsburgh, June, Some properties of linear functionals in a regular matrix space and the space of bounded sequences.

B. S. Pasternack, North Carolina State College, January, minor in Public Health, Reversal functions of a test procedure and their associated bounds when data are incomplete.

G. P. Patil, University of Michigan, June, Contributions to estimation in a class of discrete distributions.

R. G. Payton, Harvard University, June, minor in Applied Mechanics, Transient interaction of an acoustic wave with a circular cylindrical elastic shell.

P. R. Peabody, University of Illinois, June, minor in Physics, Linear transformations as integral transformations with distribution kernels.

E. A. Pflumm, New York University, February, Expansion problems arising from the Watson transform.

J. D. Pincus, New York University, June, minor in Physics, Singular integral operators on Hilbert space.

A. C. Pipkin, Brown University, June, The formulation of constitutive equations in continuum physics.

Otto Plaat, University of California, Berkeley, September, Con. tributions to the theory and applications of periodic surfaces.

R. F. Potthoff, University of North Carolina, June, Multi-dimensional incomplete block designs.

W. N. Prentice, Syracuse University, January, The mathematics of the undergraduate electrical engineering curriculum.

Frank Proschan, Stanford University, June, Polya type distributions in renewal theory with an application to an inventory problem.

W. T. Putney, III, University of Washington, June, Irreducible representations of certain matrix semigroups.

M. M. Rao, University of Minnesota, June, Properties of maximum likelihood estimators in nonstable stochastic difference equations.

Sister Mary Rose Rauen, St. Louis University, June, minor in Physics, Embedding topological spaces in topological semigroups with the same separatiou properties.

D. K. Ray Chaudhuri, University of North Carolina, August, On the application of the geometry of quadrics to the construction of partially balanced incomplete block designs and error correcting binary codes.

H. E. Reinhardt, University of Michigan, June, The use of least favorable distributions in testing composite hypotheses. 
P. A. Rejto, New York University, June, On the perturbation of integral operators of a certain kind.

J. R. Rice, California Institute of Technology, June, The characterization of best nonlinear Tchebycheff approximations.

P. B. Richards, Case Institute of Technology, June, Plane potential flow past an obstacle in a straight channel.

R. W. Richardson, Jr., University of Michigan, January, Actions of the groups $S O(3)$ and $S p(1)$ on the spheres $S^{4}$ and $S^{5}$.

D. L. Richter, University of North Carolina, August, Two-stage experiments for estimating a common mean.

S. T. Rio, Oregon State College, June, On the Hammer topological system.

R. W. Rishel, University of Wisconsin, August, Area as an integral of the lengths of contours.

D. M. Roberts, Stanford University, October, Approximations to optimal policies in a dynamic inventory model.

S. M. Robinson, Duke University, June, minor in Psychology, Some properties of the fundamental solution of the parabolic equation.

Morris Rosen, Harvard University, June, minor in Engineering, Some problems in acoustic diffraction.

R. H. Rosen, University of Wisconsin, August, Imbeddings of decompositions of 3-space.

N. S. Rosenfeld, Yale University, June, The eigenvalues of singular differential operators.

J. J. Rotman, University of Chicago, June, Mixed modules and Abelian groups.

J. D. Rutledge, Cornell University, June, A preliminary investigation of the infinitely-many-valued predicate calculus.

P. T. Rygg, Iowa State University, Ames, August, minor in Physics, The residue field of a local algebra.

Chih-Han Sah, Princeton University, June, Integral equivalence of quadratic forms in local fields of characteristic 2.

S. L. Salas, Yale University, June, Roots of real functions.

Daniel Saltz, Northwestern University, June, Averages of Fourier coefficients.

J. R. Schue, Massachusetts Institute of Technology, February, minor in American Literature, Hilbert space methods in the theory of Lie algebras.

L. A. Segel, Massachusetts Institute of Technology, September, Applications of conformal mapping to boundary perturbation problems.

T. I. Seidman, New York University, February, Linear transformations of a functional integral. 
R. H. Shaw, Purdue University, July, minor in Psychology, Multivariate classification with normal alternatives.

D. L. Shell, University of Cincinnati, June, Convergence of infinite exponentials.

J. H. Shelly, University of Illinois, June, minor in Electrical Engineering, The decision and synthesis problems in semi-modular switching theory.

P. C. Shields, Yale University, June, The theory of $B^{*}$ pairs.

E. A. Shuhany, Boston University, June, The Sj-test against linear trend.

Yasutaka Sibuya, University of California, Los Angeles, June, On nonlinear ordinary differential equations containing a parameter.

R. W. Sielaff, Illinois Institute of Technology, June, On compositive functions of matrices.

J. C. Smith, University of California, Los Angeles, June, Subalgebras defined by partial structures.

J. F. Smith, Catholic University, November, Structure theorems for certain scalar-product algebras.

R. J. Smith, University of Tennessee, December, Groups and algebraicity in complete rank rings.

R. M. Smullyan, Princeton University, June, Theory of formal systems.

Daniel Sokolowsky, University of Wisconsin, June, Some theorems on equicontinuity and retraction.

F. A. Sorensen, Carnegie Institute of Technology, June, Operating characteristics of the control chart for sample means as a test for Model I alternatives.

J. R. Stallings, Jr., Princeton University, June, Some topological proofs and extensions of Gruško's theorem.

Brother Joseph William Stander, Catholic University, June, minor in Physics, Structural forms of some special quaternion matrices.

N. R. Stanley, New York University, June, Irregular cases for the third order ordinary linear boundary-value problem.

T. H. Starks, Virginia Polytechnic Institute, June, Tests of significance for experiments involving paired comparisons.

R. M. G. S. Stemmler, University of Illinois, June, minor in Philosophy, The easier Waring problem in algebraic number fields.

C. E. Stewart, Illinois Institute of Technology, June, On singular integrals of Cauchy type and approximation theory.

T. E. Stewart, Notre Dame University, June, On compact groups.

A. P. Stokes, Notre Dame University, June, Functional analysis and some fixed point problems. 
C. R. Storey, Jr., Tulane University, June, The structure of threads.

W. G. Strang, University of California, Los Angeles, June, Difference methods for mixed boundary value problems.

Louis Sucheston, Wayne State University, June, On intersections of measurable sets.

Lee Suyemoto, University of Cincinnati, August, On complex Tauberian theorems.

J. D. Thomas, University of Oklahoma, June, minor in Physics, A local-coefficient cohomology theory for lattices.

J. G. Thompson, University of Chicago, June, A condition for a finite group to be p-normal.

W. E. Thompson, Purdue University, June, minor in Electrical Engineering, Asymptotic behavior and stability for systems of nonlinear differential equations.

R. F. Tidd, University of Buffalo, February, Non-analytic functions of a complex variable.

B. R. Toskey, University of Washington, June, Ordered products of commutative rings.

J. F. Traub, Columbia University, June, Variational calculations on the $2^{3} S$ and $2^{3} P$ states of helium.

Yih-O Tu, Rensselaer Polytechnic Institute, June, Dynamics of elastic systems under initial stress.

M. E. Turner, Jr., North Carolina State College, August, minor in Physiology, The single process law-a study in nonlinear regression.

Sister Mary Alberta Uzendoski, St. Louis University, June, $A n$ extension of the theory of cumulative frequency functions to $n$ variables.

Richard Van Blerkom, Harvard University, June, minor in Engineering, The magnetohydrodynamic flow past a sphere.

D. E. Varberg, University of Minnesota, July, Some RadonNikodym derivatives associated with stochastic processes.

Sadanand Verma, Wayne State University, January, minor in Physics, Relation between abstract homotopy and geometric homotopy.

G. D. Waldman, Brown University, June, Extended hypersonic small-disturbance theory.

R. J. Warne, University of Tennessee, June, Topological groupoids.

D. L. Weeks, Oklahoma State University, August, Variance components in two-way classification models.

Harry Weingarten, George Washington University, June, The law of large numbers and related theorems.

W. T. Wells, North Carolina State College, May, Some contributions to the solution of some statistical problems in the exterior ballistics of spin-stabilized rockets.

E. H. Wetherell, Syracuse University, January, Local behavior of 
solutions of elliptic systems of partial differential equations.

E. F. Wilde, University of Illinois, October, On groups of order $3^{m}$ and class 3 generated by five operators.

W. L. Wilson, Jr., University of California, Los Angeles, June, $A$ computational attack on the problem of plateau.

J. A. Wolf, University of Chicago, December, On the manifolds covered by a given compact connected Riemannian homogeneous manifold.

W. J. Wong, Harvard University, June, On the irreducible modular representations of finite classical groups.

C. R. B. Wright, University of Wisconsin, August, On groups of exponent four.

P. B. Yale, Harvard University, June, A characterization of congruence groups in geometries of the Euclidean type.

D. L. Yarmush, Princeton University, June, Preliminaries to a dynamic theory of zero-sum two-person games.

Zvei-Zong Yeh, Princeton University, June, Higher inverse limits and homology theories.

Neal Zierler, Harvard University, June, On general measure theory.

W. J. Zimmer, Purdue University, June, minor in Physics, Sampling inspection with a given discriminating power.

N. R. Zitron, New York University, February, minor in Physics, Higher order approximations in multiple scattering.

The following doctorates were conferred in 1958, but were not included in the list in the preceding volume of this Bulletin (vol. 65, pp. 170-182):

I. S. Bangdiwala, North Carolina State College, July, Some sequential procedures for ordering populations according to means, variances and regression coefficients.

J. E. Burke, Stanford University, October, Scattering of surface waves on an infinitely deep fluid.

J. L. Folks, Iowa State University, Ames, June, Comparison of designs for exploration of response relationships.

Jerome Freier, New York University, February, On the convergence and stability of solutions of the Cauchy problem for elliptic difference equations.

Norman Grossman, New York University, June, The elastica of arbitrary width.

R. E. Kalaba, New York University, February, On nonlinear differential equations, the maximum operation and monotone convergence.

J. C. Koop, North Carolina State College, February, minor in Rural Sociology, Contributions to the general theory of sampling finite 
populations without replacement and with unequal probabilities.

Leon Kotin, New York University, June, Transcendental equations in electromagnetic theory.

L. L. Lasman, North Carolina State College, July, minor in Economics, Asymptotic distribution of sampling size for certain methods of sequential sampling.

B. R. Levy, New York University, February, Diffraction by a smooth object.

D. E. Levy, New York University, June, A numerical scheme for solving a boundary value problem for the Tricomi equation.

R. M. Lewis, New York University, February, Discontinuous initial value problems and asymptotic expansion of steady-state solutions.

Martin Lipschutz, New York University, June, On the exterior problem for the elastic body equation $\mu \Delta U+(\mu+\lambda) \nabla\left(\Delta^{\prime} U\right)+\omega^{2} p U=0$.

S. V. Parter, New York University, February, On mapping of multiply connected domains by solutions of partial differential equations.

Stanley Preiser, New York University, February, An investigation of biorthogonal polynomials derivable from ordinary differential equations of the third order.

B. D. Seckler, New York University, February, Diffraction in homogeneous media.

C. B. Sensenig, New York University, June, Existence and uniqueness for a third order non-linear partial differential equation.

Harold Shulman, New York University, June, Mixed initialboundary value problems for symmetric implications.

Bernard Sohmer, New York University, June, Cohomology theory in groups.

Donald Solitar, New York University, February, On subgroup theorems.

H. L. Taylor, Iowa State University (Ames), November, Statistical sampling for soil mapping surveys.

Peter Ungar, New York University, June, The relations between single partial differential equations of higher order and first order systems.

Burton Wendroff, New York University, February, Finite difference approximations to solutions of partial differential equations.

Stanley Winkler, New York University, February, On coexistence for Hill's equations.

The following doctorate was conferred in 1957, but was not included in the lists in any of the preceding volumes of this Bulletin:

Henry Polowy, New York University, October, The implications of the modern probability theory for algebra. 